\title{
TEACHING ENGLISH AS A SOCIAL PRACTICE: A PRACTICAL GUIDE
}

\author{
M. H. Kepe* \\ e-mail: mzukisikepe1969@gmail.com / mkepe@ufh.ac.za
}

\author{
M. A. Linake* \\ e-mail: mkganedi@ufh.ac.za
}

*Faculty of Education

University of Fort Hare

Alice, South Africa

\section{ABSTRACT}

Pupils lack the joys and delights of literacy, whilst pressured into learning by memorisation (rote). Such examples are: initiating discussions with the schoolteacher, developing essential or analytical observations regarding their surroundings and elements, whilst discovering text interconnectedness, possibly achieved through reading. Numerous teachers are perceived as unsure concerning generating a need amongst learners to focus on instructions. This study demonstrates poetry as a solution for this challenge. The study focusses on ways, teaching English as a social practice, using a literacy process observation amongst High School De Vos Malan's pupils in King Williams Town in the Province of the Eastern Cape, South Africa. The "Atwell Reading Workshop" is used for data collection. The study is identified, using a qualitative and interpretive approach. This study concentrates on four reading alleviations workshops: Reading and interpreting a selected book, scheduled at specific times in the chosen educational institute; fundamental inspiration; observing the literacy progression; poetry reading and involvement of pupils. This study is informed by "Foucault's Critical Discourse Analysis", representing a theoretical framework. This research shows that no other literature type can be equal to that of poetry teaching. Poetry teaching represents expressions, meticulous intense wording, the significance of a nonfictional opinion, dialogue forms and the prominence thereof, the splendour of allegorical linguistics and therefore the necessity of correct punctuation and descriptive linguistics.

Keywords: Literacy view process, "Critical Discourse Analysis, Environmentalism, Fundamental motivation, Reading education

\section{INTRODUCTION/BACKGROUND}

This study induced, although several African countries and countries globally, advanced addressing of literacy in schools; the children who still do not benefit from this, appear to be disproportionately deficient, specifically where their home language (HL) is not English (Stranger-Johannessen and Norton 2017). Regarding this aspect, the study contends, whilst efforts to upsurge the quality of global primary education appear to develop, inadequate 
consideration is provided to previously disadvantaged children where their HL is not English. The contingency supposedly provided for a distinction or judgement of individual students and their activities. Their initiative and spontaneity in South Rote learning appears to obstruct and overshadow African public schools (Hoadley 2018). This authoritarian teaching style caused more harm than good and too often manifests in a form of marking time, surface learning, collective chanting and rite of rote. In rote learning a teacher occupies the centre stage instead of the learner.

The paradigm is High School De Vos Malan where this study was conducted. The situation was disturbing, with adverse consequences to most English First Additional Language (EFAL) pupils, leading to a cycle of failed reading and writing academic outcomes. This system was incorporated, despite two major curriculum changes consecutively introduced by the South African democratic regime, established in 1994, following the demise of Apartheid. For this reason, this study supports a need for an unorthodox alternative of teaching English as First Additional Language (EFAL), relating to a social practice through the lenses of Freire and Macedo's literacy process view. The following quotation from Freire and Macedo summarises a literacy process view:

\footnotetext{
"Reading the world always precedes the word and reading the world implies continually reading the word ... in a way however, we can continue and precede merely by reading the world, but by a certain form of writing it, rewriting, of transforming it by means of conscious, practical work" (Freire and Macedo 1987, 15-21)
}

The aforementioned suggests transmitting typical transmission model of teaching authorised knowledge, might not amalgamate as a view of literacy meant to empower pupils rather than disempower them through an authoritarian view of learning. Such a position evokes a "banking concept" (Freire 1993, 72), of education pursuing accumulated teacher knowledge as the ultimate education aim.

Quality education through a literacy process view in this study, can be measured by findings of the "International Association for the Evaluation of Educational Achievement" (IEA Guidebook 1998) utilising the Progress in International Reading Literacy Study (PIRLS) and the Trends in International Mathematics and Science Study (TIMSS) as they remain closely linked. This study focussed on PIRLS, in line with the central theme besought to investigate how EFAL can be taught as a social practice through a literacy process view. A literacy process view, as explained below, appeared convenient as a device to improve English acquisition in the context of this study. This view indicates a scaffold, enticing participants to read and write independently and free of anxiety and assessment test obligations. 


\section{A LITERACY PROCESS VIEW}

Contrary to the positivist notions of literacy, the aim is to submit to a literacy process view. Such a literacy process view, centres on a metacommunicative ability. The term metacommunicative ability indicates a growing awareness and control over social means, whilst pupils develop a discourse, enabling an attempt to co-create knowledge and experience. Their (participants/pupils) act of reading and writing may represent their social involvement/social practice. Consequently, the students would realise that a sustaining meaning in reading and writing requires them to maintain the reading and writing process (Rosenblatt 1978). This implies that they will not be overly concerned with "what does that say?" or "what do I make that say?" (Sivasubramaniam 2011, 69).

As their words, putting in writing, would or might reveal, they may be concerned with keeping the process of reading and writing valid. This is in line with process reading, utilised in this study, where pupils/participants used Reading and interpreting a selected book, scheduled at specific times in the chosen educational institute; fundamental inspiration; observing the literacy progression; poetry reading and involvement of pupils (Atwell 2006) as interpretive practice avenues. This indicated that they could learn to improve their writing by progressing with the range of increasing responsiveness as found in this study. These pupils' systematic skills might improve, narrating their reading and writing experimental qualities.

Conversely, a literacy process view utilised in this study, provided participants with what Adamson, Coulson and Fujimoto-Adamson $(2019,21)$ refer to it as an "agency". During this process, competent students might not observe their text through immovable artefacts, as an alternative, text might be used to evolve and create significances, overcoming fixture of a script when used for producing objective meanings (Rosenblatt 1978).

Considering the aforementioned information, scripts can seem sensible to individuals merely in potential informative routine approaches, which cannot be determined with a factual, inaccessible communication language location (Rosenblatt 1978). Conversely, Interpretive practice can also serve to illustrate the message-rich and involvement-poor (Brandt 1990) writing of individuals, observing the text as a self-sufficient and self-referential instrument of literacy (Rosenblatt 1978).

A literacy process view is therefore synonymous with social interpretive practices, involvement and metacommunicative ability with a capacity to read the word (Rosenblatt 1978). Contending a literacy process view, the study aspired to focus on text functions, whilst teaching pupils to read the world. If interpretive practice does not relate to articulating knowledge of the world, the practice should be dismissed as unfruitful (Sivasubramaniam 
2011). Using literacy as social practice, can address the dynamic and dialectical link between words and worlds. In this concern, "the command of reading and writing is achieved, commencing with words and themes, meaningful to mutual experiences of those becoming literate; this excludes words and themes linked only to the experience of the educator" (Adamson et al. 2019, 20-21). Considering this observation, the students' factual reading and interpretation do not include the routinely learnt recurrence reading technique of reality.

Similarly, the PIRLS 2017/18 report results, wherein 78 per cent of South African Grade 4 children reported to be unable to read for meaning in any language, appear to be consistent with the aforementioned assertions. This report intrinsically, is distressing as it might exacerbate the ever-escalating decline of the matric academic performance, specifically in the Eastern Cape, the natural setting of this study. If the inability to read and write is not addressed, may have long-term serious repercussions, leading to misunderstanding instructions and concepts by students across subjects. This was the case before in the English First Additional Language (Pupils exploiting EFAL) class at High School De Vos Malan (Kepe 2017). This study therefore advocates for an unconventional approach to rote learning, which is to teach EFAL as a social practice through a literacy process view.

The Critical Discourse Analysis emphasises the aforementioned observation of language as action and societal conduct, establishing: "discourse - the use of language in speech and writing as a form of social practice” (Kepe 2017, 77).

Discourse in Foucault's terms, "governs the way that a topic is meaningfully discussed. It also influences how ideas are put into practice. It is also used to regulate the other individuals' conduct. This indicates discourses (or discourses in the social theoretical sense) limits and restricts, other ways of talking and producing knowledge" (Hall 2000, 346) ensuring a literacy process, enabling pupils to improve their speaking, writing and reading skills. Discourse in this sense, should embody spoken and written texts, with each being able to construct and identify its interlocutors. It is crucial that students should use a literacy process view, holding a critical understanding of the discourses around them to avert misunderstanding or misinterpretation in and outside the classroom. This pedagogy-focussed study explored how FAL could be taught as a social practice through the literacy process view. For Stranger-Johannessen and Norton (2017) the language of instruction concern designates a combative matter in Africa, sternly disputed by the media and recurrently focussed on in academic literature.

In this concern, WorldAtlas.com (2018) estimated 2000 languages spoken in Africa and only a few, mostly small countries, such as Botswana, Burundi, Lesotho, Madagascar, Rwanda, Somalia and Swaziland and some small island states in Sub-Saharan Africa use one language for the greater part of its population. The abundant use of languages, coinciding with biased 
history, encouraged the use of colonial languages such as English, French and Portuguese as the medium of instruction (Wolff 2016a). The study established ways of teaching EFAL as a social practice through the literacy process view in a South African school.

This study provides evidence that offered learning materials, such as fairy-tale reading material and books with poems as crucial for literacy improvement and to acquire a global or additional language (Krashen 2004; Clark and Rumbold 2006; Garan and DeVoogd 2008). This study focussed on determining ways of teaching English as First Additional Language through social practice, exploiting a literacy process view. The study observation is that such textbooks are vital for advancing knowledge in the native language, whilst functioning as the groundwork for literacy development in alternative languages, such as English, isiXhosa, Afrikaans and French, amongst others (Cummins, Brown and Sayers 2007).

Conversely, during schooling initiation, educators profoundly trusted "chalk and talk" (teacher centred approach), indicating their primary literacy teaching means (and other subjects). Teachers therefore lacked opportunities to advance teaching methods, using books with fables and poetry during their lessons (Stranger-Johannessen and Norton 2017); teachers and pupils appear to battle with literacy, specifically with English and African Languages.

This phenomenon appears across the globe, specifically in the Non-Anglophone countries, such as Norway, Denmark, Sweden, Iceland and Finland, amongst others. Africa appears to be the most affected: Khalifa Said, the reporter of the Tanzaniannewspaper: reported through The Citizen (2016) that the latest literacy study where the old habit involved, "turning the page with a flick of a finger, not the click of the mouse, was slowly dying a natural death" (Khalifa Said 2016, paragraphs 6-9). Given this, in South Africa, Uganda, Tanzania, Nigeria, Ethiopia, Kenya, Ghana, Ivory Coast and Zambia the steady decline in the popularity of the newspaper appears to have levelled off after several years sliding (Khalifa Said 2016).

Several assumptions remain unchallenged to teaching reading and writing and which languages to use. Whilst this narrative remained unresolved, pupils with reading problems are entangled in a negative cycle of failed reading outcomes and academic underperformance (Hendricks 2013). This study investigated how EFAL can be taught as a social practice, using a literacy process view amongst pupils of High School Devos Malan, King Williams Town (in the Province of the Eastern Cape, South Africa).

As aforementioned, this analysis results from longitudinal ethnographic case study research conducted at High School De Vos Malan in King Williams Town in the Eastern Cape Province of South Africa. The thesis took three academic years to be completed. It comprised 36 learners, followed from Grade 10 to 12 from 2014 to 2016 for continuity, whilst observing their progression within the period. The methodology section will elaborate on this concern. 
This study comprised a sample of 18 pupils and 10 teachers. From ten teachers, three teachers taught English as Home Language (HL) for Grade 10 to 12. Seven teachers taught content subjects for Grade 10 to 12 . These seven teachers include the principal, also teaching mathematics and his deputy who taught accounting. The principal taught mathematics for Grade 9 and 11. The deputy taught accounting for Grade 10 to 12. There were also two Head of Departments (HODs), one representing physical science and the other, mathematics. One teacher taught history and the other taught Afrikaans HL. Another teacher taught Life Orientation. High School De Vos Malan is a comprehensive multiracial school, commencing with Grade R up to Grade 12. As aforementioned, it is situated at the hub of King William's town district in the Province of the Eastern Cape.

The school is diverse, comprising isiXhosa speaking pupils, amongst others. Some of these pupils use English or Afrikaans as their Home Language. Some are multiracial ethnic group Afrikaans native speakers; some chose English as their HL; Indian pupils (Hindi native speakers) utilised English as HL and some white Afrikaans natives also preferred English as their HL in school. High School De Vos Malan used English and Afrikaans as medium of instruction where pupils would either use one of the two languages from Grade 1 up to Grade 12. Concerns are parallel in this school. The instruction in Grades 10 to 12 commenced to blend languages for further clarity of the subject matter or content, provided the nature of the diverse classes, where the Afrikaans natives were introduced to English terminology and English natives introduced to Afrikaans as their First Additional to assist with content comprehension.

Even though the school hold a dual medium of instruction (English and Afrikaans), multilingualism through code switching characterised the learning situation, which did not form the theme of this study. This study besought to determine how EFAL can be taught as a social practice through a literacy process view in a school. Having such a combined input of pupils in one school proved to have its own limitations. This can be explained through the lenses of Hendricks (2013), who observed that in South Africa, predominantly in the Eastern Cape Province, homes have inadequate reading material for children, beyond the Bible. Community libraries are rare in rural areas as they hold a limited vocabulary and are inclined to misunderstand instructions. Research exacerbated this concern, indicating that 93 per cent of public schools have a shortage of library resources or librarians, yet unfortunately, Government reduced budgets to school libraries, including providing non-textbook reading material. This adversely affected learners' academic performance, particularly those from less affluent families as most could only speak English in school. Beyond school hours, they revert to their mother tongue (isiXhosa/Afrikaans). This invokes Witt $(2003,2)$ who extrapolates that "... difficulties with reading literacy, if not addressed, then permeate all future educational 
undertaking as the divergence between their reading literacy skills and the demands of the curriculum widens".

If the PIRLS (2017/18) report is observed with 78 per cent Grade 4 children in South Africa who are unable to read, it can be concluded that South Africa lags far behind other countries. Contrasting this percentage with a country such as America, representing only 4 per cent and in England 3 per cent who are illiterate. The comparison appears relevant because if a developing country such as South Africa, wants to excel, it must be compared with the best.

Notwithstanding that the same report was conducted amongst the middle-income countries, such as Iran, indicating that 35 per cent of Grade 4 pupils could not read for meaning. The figure in Chile was only 13 per cent (Mullis, Martin, Foy and Drucker 2012).

The report indicates that South Africa rated last concerning literacy amongst fifty countries. This forms a pattern, as a declining number of South African students who cannot read, continue to debilitate. Only 3 per cent of South African Grade 4 students reached the High International Benchmark. In 2016 only 2 per cent reached this benchmark (Mullis, Martin, Foy and Drucker 2012).

The aforementioned situation invokes Dyer, Shatz and Wellman (2000), observing that children from underprivileged backgrounds in England who often engage in reading activities, perform better academically than children who have educated parents but do not indulge in reading. The same study indicates that the youth who read for pleasure performed better, not only in language classes but also in maths, established in all subjects. Considering the aforementioned statement, supporting the justification, the justification supports additionally claims, specifically related to the question: "How can the English FAL be taught as a social practice through a literacy process view?" This question is dealt with in the latter part of the study. The study advocates that a central community lacks, where norms or standards of English competence for all communities can be defined, therefore competence in academic language employs a holistic construct, needing to be pluralised to reflect the broad diversity of global settings where it is used (Nunn and Langille 2016).

\section{LITERATURE REVIEW}

This section attempts to suggest alternative approaches by locating this study within the context of the existing literature. Certain aspects are explained, constituting the literacy process view serving as a stimulus for improving EFAL at High School De Vos Malan in this study. The literacy process observed, mainly comprised four aspects: Reading and interpreting a selected book, scheduled at specific times in the chosen educational institute; fundamental inspiration; observing the literacy progression; poetry reading and involvement of pupils. (Atwell 2006). 
Since the aforementioned aspects are interwoven and inextricably linked, they cannot be explained in isolation. These aspects will assist unpacking the literacy process view in the context of this study. This study reasoned that students are in a disadvantaged position because they appear to lack study skills, writing skills, summarisation, critical thinking and examination skills because of their long-term exposure to rote learning. Such a deficiency might have led to their reliance on the traditional notion of grammar-translation methods employed since primary/elementary level where they appeared to learn through "a continuous process of rote memorisation that they got used to ..." (Sivasubramaniam 2011, 188).

This factor continues to influence them, even at university level. The situation can be compared with a house built without a concrete foundation that would show some cracks at a later stage. Considering this aspect, the study advocates for teaching EFAL as a social practice through a literacy process view. The study contends that incorporating such principles into the curriculum should be performed with a holistic approach, using a literacy process view, regarding learning and teaching, such as "nurturing a sense of wholeness in enquiring minds, encouraging negotiation and facilitating learning through dialogue" (Nunn and Langille 2016, 302-316) to enable pupils and teachers to constantly choose appropriate techniques and methods concerning evolving situations.

\section{THEORETICAL FRAMEWORK}

Theoretically, this study is premised within Foucault's (1981) Critical Discourse Analysis (CDA). Extensive reading, identity and culture are constructed discursively in this study, using EFAL as a social practice. The analysis of discourse pertains to the analysis of the language applied. Kepe (2017) paraphrase discourse as "a culturally and socially organised method of dialogue where the context of interaction is crucial to meaning making" $(2017,74)$. This consolidated definition leads to identifying the function of a reading workshop in this study, explained below.

\section{READING WORKSHOP}

Atwell (2006) describes a reading workshop as "an instructional practice that may assist children to grow as readers, speakers and independent thinkers" (Atwell 2006, 26). As exhibited in Kepe (2017), pupils can create a literary community through reading workshops, enthusiastic about reading, whilst engaging in becoming fluent readers and thinkers, leading to a literacy process view. As a class teacher and a researcher, the research conductor was able to create a fear free environment. This was exhibited by the role the participants played in their classroom corner library where they enjoyed a freedom to select a book they like. Pupils were afforded 
reading time through Uninterrupted Sustained Silent Reading (USSR) and received guidance.

The ability existed to teach reading to children, ensuring their reading ability to enable them to learn. Conversely, understanding the reading material, whilst enjoying the reading process were complex. Bearing this in mind, the pupils needed time to develop these skills.

They had to be devised to create an environment, supporting their growth and independent reading skills, pursuing book sponsors from NGOs such as Read and provincial libraries. The privileged was requested to bring available reading material from home. Parents were also engaged to sponsor reading material for the reading workshop.

In the context of this study, structures, such as classroom corner libraries and the big reading box were made available for the readers, reading what they find interesting: From fiction to nonfiction, from graphic reading material to magazines and news reports from printed and digital resources. The aim of the reading workshop was to provide time for pupils to read. Time made the difference in learners', whilst growing as readers. Emphasis was on managing pupils' self-governing reading during poetry classes. Demonstration assisted readers to easily construct their own poems (e.g. the "I" poem).

This was a starting line, using their own experiences to develop skills and strategies to read increasingly complex text. Towards concluding the children were required, during the lesson, to read aloud, be it a peer reading/shared reading/group/reading aloud, or whilst presenting their poems through a poster in class. The shared time added closure and a sense of celebration. The photograph labelled Corner library image A may assist to amplify how display was employed with the reading material removed from the handmade shelves of our classroom corner library.

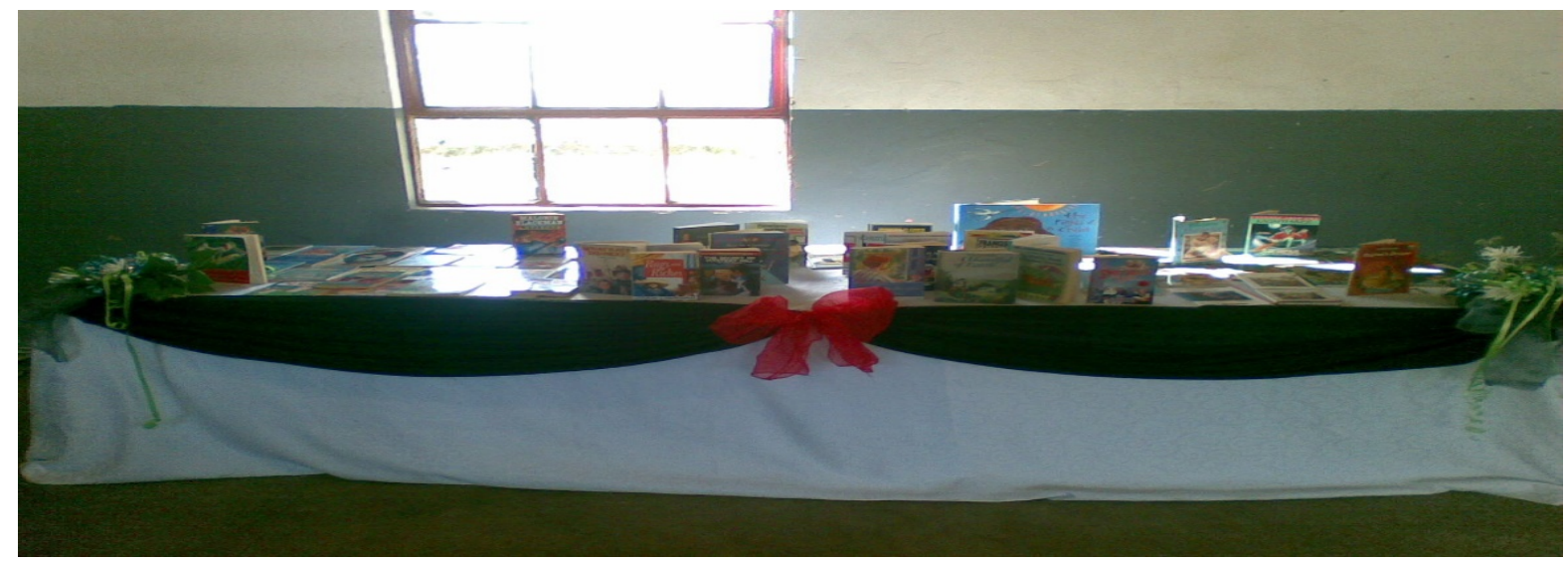

Corner library image A

The above display was meant to entice and imbibed their thirst for reading. This signifies only one aspect of the reading workshop. Importantly, the reading material had to be contemporary 
whether fiction/non-fiction/magazines/graphic reading material or newspaper reports. Reading was also modelled and recommended. A strategically awareness was present, not to overshadow independent reading, which forms a pillar of a literacy process view. Activities, such as narration, dialogue, debates and roleplays were exhibited in the context of this project. The study then progressed to the function of poetry in the reading workshop.

\section{THE FUNCTION OF POETRY}

Atwell (2006a) emphasises that poetry unassumingly assists individuals in self-understanding and knowledge on the requirements of high schoolers/adolescents. She states: "The lesson poetry teaches kids concerns good writing, critical reading, the kind of adults they wish to become and the kind of world they hope to inhabit, extend the best invitation I can image to grow up smart, healthy, and whole" (Atwell 2006a, 26). This invokes Smith (1986) observing that adolescents are looking for role models consequently, if a teacher models reading then pupils are prone to become readers as was in (Kepe 2017). Conversely, pupils who want to feel competent and in control of their lives, pursue role models in peers and adults. This is where the influence of poetry becomes significant. Poetry further communicates the goals of this research, since it was established that reading amongst pupils as a stimulus, inciting a learner to become a critical reader and a proficient writer, whilst becoming a fluent, eloquent speaker. In this regard, poetry became the mainstay of the curriculum for its brevity and generosity (Atwell 2006a).

In view of these aspects, pupils find poetry appealing as they either find or draft a poem concerning interesting subjects from comic book heroes to prejudice. Pupils drafting their own poems, may travel farther into the genre, as explained below: An "I Am", (Fall 2013, 9-10) poem was utilised to develop love for poetry. This was often used during the study as an icebreaker in the classroom with participants at High School De Vos Malan. Participants' involvement would be to write an "I Am" poem about their own self. The "I Am" poem expressed the way they feel, their hopes, their thinking, dreams and enjoyment amongst others. Each "I Am" poem comprised specific mutual elements. The lines in "I am poem" were recited in class, started with words: "I know", "I think", "I feel” "I say" I smell and "I hear" (Fall 2013, 9-10) amongst others. Some sentences in the poems described resonated their imaginations, sounds and experiences (presenting figurative language).

Other sentences expressed actual, literal emotions. The first line in their "I am" poems, was repeated during the conclusion of each stanza. In the research conductor's view this was a manifestation of literacy. 


\section{LITERACY}

Provided the complex relationship between verbal and written language, a linguistic notion of literacy might prove to be unbeneficial. It might discard the available focus on the controversies, encompassing "text" (Kern 2000). The study did not model on a view of literacy, which is usage centred; literacy would employ a use-centred model where the learner is empowered through interpretive practices. The study focussed on cultural awareness and critical reflection (Kepe 2017). The goal of such literacy is parallel with the "extensive reading" approach. It is not free from social influences, linking individuals and the populace (Vygotsky 1978). Kern's (2000, 35), observation corresponds with Vygotsky (1978), stating that literacy is not the "personal, idiosyncratic property of an individual, but rather a phenomenon created by society and shared and changed by the members of that society".

\section{METHODOLOGY}

Concerning the paradigm, the study is interpretive, based on a qualitative method. This suggests that it is a narrative of the perspectives of the researched population deduced from the Atwell's Reading Workshop (2006a). As it was a qualitative research, triangulation was necessary through devices used to collect data. Data ascertain credibility and trustworthiness. CDA is consistent with social constructionism, underpinned this study.

\section{DATA COLLECTION DEVICES}

Through the metaphorical categorisation of data collected and with the assistance of the theoretical underpinning from the literature review, the study used the following intertwined aspects from the Atwell's Reading Workshop as devices to collect data: Reading and interpreting a selected book, scheduled at specific times in the chosen educational institute; fundamental inspiration; observing the literacy progression; poetry reading and involvement of pupils. Based on significant data collected and limited space in this study, it was impossible to utilise all information.

As the devices were interwoven and inextricably linked from the listed above, only two were selected: Reading and interpreting a selected book, scheduled at specific times in the chosen educational institute, poetry reading and involvement of pupils. Since the focus of the study was on teaching EFAL as social practice through reading extensively in a South African school. Based on this factor, it was proposed to shape consecutive narratives and interpretations. The aforementioned devices in the context of the main question, fused in as the central theme in this study are explained, questioning:

- How can the English First Additional Language be taught as a Social Practice through a 
Literacy Process View in a South African school?

\section{READING AND INTERPRETING A SELECTED BOOK, SCHEDULED AT SPECIFIC TIMES AT HIGH SCHOOL DE VOS MALAN}

During this time, pupils read for an extended period at their own reading levels. This was in consistence with the study's firm belief that reading and responding are central to the literacy process view. This was observed in the USSR programme established concurrently during this study. Eighteen participants (learners) read independently and widely for enjoyment. As proof that reading indeed occurred during that time, participants would read and then react/reflect on the reading material read, such as any fiction/nonfiction selected books, graphic books, magazines or newspaper articles. Due to its efficiency and productivity, this process was endorsed and accommodated by High School De Vos Malan's School Management Team (SMT) as intrinsic to an English First Additional Language class timetable during the English FAL lesson.

Certain SMT participants in this study, applauded the productivity of the USSR where pupils had a first-time opportunity to read and select interpreting book and read for joy. Endeavouring to enrich the programme, the study used a corner classroom library and managed to obtain book sponsors from the Eastern Cape Provincial Archive.

Participants brought various magazines and newspapers from home to the reading box. The USSR was observed as an aspect of the subheading: Reading and interpreting a selected book and fit in to the English period where, before any lesson of the day commences, participants were provided 15 minutes to read silently. Due to time constraints, participants would be provided time to read homework whereby they were expected to report, react and reflect on what they read, in the form of free writing in their journals /USSR report.

This observation is consistent with the study observation that high school readers are inclined to specialise and flourish on characters close to their own age with identifiable emotions, accompanied with sensible challenges (Kepe 2017).

This statement appears valid, observed in participants' responses when they shared emotions, cried and laughed with characters in their USSR reports in the reading zone. It was fascinating in this programme to establish that participants actively engaged with reading material and reacted afterwards. Atwell (2007b) stresses that teachers should recognise learners' inclination (preference) as readers and provide them with books, matching their reading ability and interests.

Learners' choice became a strong motivator and opportunities were created and initiated for them to engage in. Failure might have resulted in a lack of opportunities for regular, engaged 
reading. This indicates that the environment for reading was appealing.

High schoolers teachers are aware that especially at an adolescent age, pupils must be treated as individuals. Pupils are expected to become independent readers. Yet, often they are provided with limited opportunities to investigate their own interests in reading; to read at their own pace, or to make their own decisions concerning book reading. High school teachers need to reform to develop and become lifelong readers. Several leading reading teachers, including Atwell (2006a) and Kepe (2017) argue that learners' ownership is crucial for a reading workshop. Instead of trying to persuade pupils to read all revered as "great literature," pupils should be engaged in conversations on the uses they have for a range of texts in their own lives (Lewis 1997). The study contended for teaching EFAL as a social practice through a literacy process view. Pupils seemed to have been forced to read material that they have no interest in and did not have a choice in selecting. This created resisting reading in school. This aspect does not support the ambition of a literacy process view in schools; instead it hampers it.

\section{POETRY READING AND INVOLVEMENT OF PUPILS}

As indicated in the literature review, this study served as a scaffolding for pre-writing through poetry towards proficient writing and provided participants with the capacity to act independently and to make their own free choices. Adamson et al. (2019) referred to free choices as an agency. Emphasise in this regard was exhibited in one pair work activity where participants were requested to interview each other, based on asking the interviewee (peer) to list at least 10 items (s) he liked. From ten items mentioned by his/her peer(s) he was asked to use those likes to create a poem about his/her peer in the journals.

The poem would comprise 10 lines. From 10 at least 2/3/4 lines had to rhyme. Participants were also requested to endeavour to use similes and metaphors in their lines in describing each other through poetry. The study observed that even though the instructions were clear, some participants repeatedly asked for clarity. In such instances further explanations were provided. Whilst some participants appeared to be challenged by the activity, others were comfortable. Towards the conclusion of the period, numerous interactions were observed. It became more enjoyable when the final instruction directed that each one should stand and recite aloud what they wrote about each other.

\section{PARTICIPANTS}

The sample comprised 18 pupils and 10 teachers. Three teachers taught English HL from Grade 10 to 12 . Seven teachers taught content subjects from Grade 10 to 12 . Seven participants included the principal and his deputy. The principal taught mathematics for Grade 9 and 11 . 
The deputy taught accounting from Grade 10 to 12. Two HODs participated - one presented physical science and the other mathematics. One teacher taught history and the other one taught Afrikaans HL. The last teacher taught Life Orientation.

\section{EDUCATIONAL INTERVENTION}

This programme allocated 15 minutes during each period daily for EFAL learners, from Grade 10 to 12 to read for pleasure and enjoyment. Before they commenced with the lesson, pupils would read a book of their choice or magazine or a newspaper for a period of 15 minutes. The emphasis here was on Reading and interpreting a selected book, scheduled at specific times. Pupils were permitted to read because they were willing to. Reading had to be designed first through extensive reading (i.e. reading material of their age/teenagers' books) and recommending those to pupils in addition to their choice. Recommendations were made carefully to ensure that it could not temper with learners' choices. Recommendations were conducted to inspire pupils (participants) and to persuade them that the research conductor was also a reader; conversely, practising what was advocated.

It inspired some (pupils), realising that the research conductor was also a reader. An enticing learner setting/ environment for reading was constructed and built. This was achieved by searching for good, contemporary and attractive reading material appropriate for the level of pupils to prompt their desire to imbibe a reading practice. In addition to the recommendations, reading material were displayed neatly at a custom-made corner library shelves against the wall in the classroom. An established specious table and a large reading box where magazines and newspapers were kept, were structured in an accessible position to ensure pupils or readers (participants) could access further reading enjoyment.

To control the intake and returning of reading material based on requisition books, two reading coordinators (from the pupils) were elected. This was received with joy as it brought a sense of ownership to them, simultaneously teaching them responsibility. For the research conductor, representing an ethnographic researcher, this was a literacy process view in action, the rational of this study.

\section{PRESENTATION AND ANALYSIS OF DATA}

Whilst the study generated massive immense data, which might have seized beliefs and a value system, it was virtually impossible to present all data in the limited space of this study. The rigorous selection was based on the qualitative study argument of no rules in qualitative research for determining how several instances are necessary to support a conclusion or interpretation and this is always a judgement call (Taylor and Bogdan 1998). This elucidated 
on the observation that a single incident can be enough to build a conceptual category. As aforementioned, the data metaphorically suggests two categories of participants, indicating pupils and teachers. The analysis that followed in the study, employs a representative sampling for each of the above categories to introduce their perspective on teaching EFAL as social practice through a literacy process view. The categorisations of the themes were conducted discreetly for this analysis and interpretation.

The reader should be reminded that the devices used to collect data may not have been analysed and interpreted in isolation as they appear to be inextricably linked. The six devices indicated: Reading and interpreting a selected book, scheduled at specific times in the chosen educational institute, poetry reading and involvement of pupils. Reading and interpreting a selected book, scheduled at specific times at school and poetry reading and involvement of pupils were viewed as crucial components of the programme. In the representation of the data to follow, the crucial devices were depicted as segments.

Two strands of data were used for both Segment 1) a book of choice with time to read in class and Segment 2) reading and sharing poetry, ensuring that the presentation was salient. Data stretches were illustrated in the analysis by using italic fonts. For the purposes of reference and harmony, the students would be labelled as (S) and the teachers as (Teachers). As aforementioned it was essential to recognise the data collection devices in contrast with the central theme, which in this case represents the main research question, to investigate how the EFAL could be taught as a social practice through a literacy process view in a specific school. Below are the crucial devices followed by the theme:

\section{TEACHING FIRST ADDITIONAL LANGUAGE AS A SOCIAL PRACTICE THROUGH A LITERACY PROCESS VIEW}

\section{Main devices}

1) Reading and interpreting a selected book, scheduled at specific times at school.

2) Poetry reading and involvement of pupils.

Based on the above stance, instead of six themes, the study proposed one theme, fused within the main question: Teaching EFAL as social practice through a literacy process view paired with 1) Reading and interpreting a selected book, scheduled at specific times and 2) Poetry reading and involvement of pupils. The study was inclined to commence with Reading and interpreting a selected book scheduled at specific times in class since it emerges as the strongest for the purposes of data analysis. 


\section{FINDINGS}

This section relates the findings of the study to the central theme/research question. It was conducted by fusing the main research question, which joined this investigation with the two selected devices, presented in italics, contrasting with the crucial methods, such as 1) Reading and interpreting a selected book, scheduled at specific times and 2) Poetry reading and involvement of pupils. As a reminder, the main research question was crafted as follows:

- How can the English First Additional Language be taught as a Social Practice through a Literacy Process View in a South African school?

The central question/theme stated above was often realised as a lived experience of participants. As a result, the literature review identified theoretical and practical issues supporting a constructivist approach to this investigation. The theme considered in the study, facilitated a research design allowing for productively using data collection procedures as indicated below:

\section{Segment 1}

\section{Teaching EFAL Additional Language as Social Practice through a Literacy Process View}

The research conductor's function as an ethnographer and the above theme to trajectory was to maintain the tone of conceptualisation, anticipating that it might serve as a guide in the study analysis. Below are some of the data extracted from learners' perspectives regarding reading a book of choice in class in De Vos Malan School (labelled L1 and 2).

\section{Extract 1:}

L1 "Reading is the medium of education. It is the only way that we will be able to make a success of our lives one day. If you cannot accumulate this skill, you will struggle to get somewhere in life."

L2 "Without reading, people are seen as uneducated. They will struggle to find a job or in their everyday lives as reading is found everywhere."

In view of the above responses, participants (learners) appear to understand the significance of reading in their academic life. In this regard, reading is observed as the only way to improve. The data below are extracted from the teachers' perspectives concerning a book of choice in class. 


\section{Extract 2:}

Teacher 1: "In our country we have got lots of things about language and language policy. We all know that English is the language that is used internationally, and our country uses it, but you might be educated but you cannot be able to express yourself properly in English. I would say expose them as much as you can to poetry specifically in English if you want them to think critically. But also, to media (TV, Radios, newspapers, articles and magazines) and so on. I know there are issues of culture/ tradition and accent, but you know accent is what you hear, and you get used to. For example, if they are used to British or American accent, they may lose they tradition/culture. I mean we have our own slangs and South Africans, we love our own slangs, and it doesn't matter whether you speak Afrikaans/ IsiXhosa/ isiZulu. So, I think it's a social thing, yes. I mean I have travelled overseas and used the words that we as South African are used to. I think in terms of the accent we just need to be tolerant I mean people have misconception of it. Being an avid great reader myself, I mean, my mother, since the small age, will push the books to us and it doesn't matter what you read as long as you read. The problem is that as such our learners, their parents aren't reading either, so they don't get into the habit of reading. I mean stupid me I grew up reading at least one page of a book every day."

Teacher 2: "School library, cupboards, display book in and around the classroom, catalogues from book companies and show learners what's out there. We must always dramatize characters. Sometimes you feel stupid, but we ought to do that. Take any book, open it in the middle and then read where there is tension up to where it ends and then stop to attract their interest. Our learners do not have resources to go and buy books so they need a central area where they can borrow and share books."

Similarly, from the above comments, teachers recognise the need for reading with emphasis in dramatisation, comprising the purpose of this study (interaction).

\section{Segment 2 (same theme)}

\section{Teaching EFAL as social practice through a literacy process view}

The data below were extracted from learners' perspectives regarding reading and sharing poetry in school.

\section{Poetry reading and involvement of pupils}

\section{Extract 1}

L1 "Writing poems helped me to understand my own life and be able to relate with others. When I feel down it helped me to express my inner most emotions."

L2 "More than anything, poetry has helped me a lot as before it was difficult for me use the 
figures of speech but now I can because of writing poems multiple times."

From the above comments, a reader can observe that reading, sharing and constructing poetry had a positively influence, possibly leading to proficient writing, which was a major challenge across subjects in this school.

\section{Extract 2}

The data below, extracted from the teachers' perspectives concerning reading and sharing poetry in class in this particular school.

Teacher 1: "Poetry teaches students about critical reading, and the kind of adults they wish to become and the kind of world they hope to live in."

Teacher 2: "Poetry inspires students to think deep as they can find or create a poem on any appealing subject from including expressing their feelings when they are hurt or happy."

The comments echoed by the teachers above are in concert with the rational of this study, seeking to encourage a socially and culturally organised teaching method through the reading materials and poetry in which the context of interaction is crucial to meaning making (social practice through a literacy process view).

\section{DISCUSSION OF FINDINGS}

The objective of this study was to determine how EFAL can be taught as a social practice through a literacy process view. In view of this, this study revealed that for pupils to succeed in both EFAL deficit and in their studies across subjects in this school, they do not only need knowledge of English as instruction language and a social practice, but they also need to have a good knowledge of the cultures of those they interact with. This study employed an ethnographic design to investigate ways EFAL could be taught as a social practice through a literacy process view in a school. The research population was based on purposive sampling and participants were selected, based on judging their typicality (Kohonen et al. 2001).

The USSR was fitted into the English period before the lesson of the day for 15 minutes. Due to time constraints, participants were provided with reading homework. They were expected to report and reflect from what they read in the form of the USSR report/journal writing. This is consistent with the findings of this study that high school readers are inclined to specialise and flourish on characters close to their own age with recognisable emotions and realistic challenges. This study also revealed that poetry as a device, was effective in engaging 
participants' interactions in class, evident when sharing emotions, cried and laughed with characters in the reading workshop. Importantly, what was fascinating in this programme was to establish participants actively engaging with reading material and reacting afterwards.

The study revealed that teachers should recognise learners' inclination (preference) as readers and provide them with reading material matching their reading ability and interests. This was a case in this study where learners' choice became a strong motivator (Gardner 1985). This invokes Atwell (2007b), postulating that teachers need to create and initiate opportunities for pupils to engage, but failure may result in a lack of opportunities for regular, engaged reading. This indicates that the environment for reading should be appealing. Teachers should establish the scene. Organise attractive contemporary "good books" appropriate to pupils' level. Otherwise, falling short of this may assist identifying reasons why most pupils are poor readers upon entry into high education (Adamson et al. 2019). This study revealed that fostering pupils to become engaged readers, the teacher enables them to gain competence and self-efficacy (Rosenblatt 1995).

The study also revealed the importance of intrinsic motivation (Gardner 1985), in which teachers are crucial in establishing the stage and stimulating the desire to read for pleasure. This invokes Rosenblatt (1978) who mentions poetry as a major device through which language structure can be accomplished contingent on the passion and skilfulness of the teacher concern. Her assertion aforementioned agree with participants' observations that reading must commence from a young age. More reading material should be to the avail of pupils to relate themselves with. Simultaneously, it was also participants' view that schools need to be furnished with a school library and cupboards, displaying reading materials in and around the classroom. This includes catalogues from book companies where pupils indicated the availability of choice.

\section{RECOMMENDATIONS}

- The study recommended a need for teachers to impart knowledge of English as the language of instruction, but they should consider the social context of learners, such as a need to good knowledge of the cultures of the others that they interact with.

- The study recommended that if the high school readers are afforded agency through the means of a literacy process view, they specialise and flourish on characters close to their own age with recognisable emotions and realistic challenges.

- This study also revealed that poetry as a device, was effective in engaging participants' interactions in class. 
- It revealed that teachers should recognise learners' inclination (preference) as readers and provide them with reading material that match their reading ability and interests.

- It revealed that teachers need to create and initiate opportunities for pupils to engage, because failing may result in a lack of opportunities for regular, engaged reading.

- This study revealed that the environment for reading should be appealing and that teachers as mediators of knowledge should establish the scene.

- This study revealed that teachers need to organise attractive contemporary "good books" appropriate to learners' level, fostering pupils to become engaged readers and gain competence and self-efficacy.

- The study revealed the importance of intrinsic motivation where teachers are vital in establishing the stage and stimulating a desire to read for pleasure.

- The study revealed that poetry is one of the major devices through which language structure can be accomplished contingent on the passion and skilfulness of the teacher concern.

- This study revealed that reading must commence at a youthful age and that there should be more reading material that pupils could relate to.

\section{Implications of the study}

- This study implicated a passion for reading, which should be instilled at an early age and commence preferably from home and be strengthened at primary schools. This would assist because by the time pupils reach secondary school, they are already fond of reading and have become readers. In the same breadth, this may culminate into improved results at Grade 12 because language would not indicate a challenge or a barrier.

- Implications on teaching content subjects: It is well known that reading turn ordinary pupils into readers, which are analytical, critical, interrogative, diagnostic, systematic, logical and investigative thinkers. Considering this, pupils would have less battles with concepts. Pupils are known to fail examinations because they are unable to read instruction. Good readers would understand instructions and questions because they are familiar with the vocabulary used in the content. Since research indicates a strong correlation between reading proficiency and academic success at all ages, as the strategies suggested earlier towards teaching EFAL as a social practice through a literacy process view in a school, can contribute towards better results. 


\section{LIMITATIONS OF THE STUDY}

Concerning the limitations, the main challenge was the time as an insider, so it was needed to balance teaching time with study. Concerning (teachers) as participants break times had to be targeted and the free periods hold interviews and also to remind or galvanise participants for data collection. In some instances, the study would utilise holidays or even the weekends by arranging appointments, depending on the participant's availability, especially with teachers (participants) or at the least even call participants as a reminder and persuade them to complete a questionnaire for the purposes of data collection. Even though, there was some degree of procrastination by some participants (teachers) concerning data completion and delaying tactics, such as convening interviews sighting busy schedules, polite communication skills and patience with them, ultimately prevailed.

\section{CONCLUSION}

This investigation was mainly intended to examine whether EFAL could be taught as a social practice through a literacy process view in High School De Vos Malan. The findings collected from this study verified that cognitive and social interactive approaches should be encompassed within the constructivist epistemology to assist participants in becoming competent in EFAL. Findings of this study attired towards advancing teaching of the EFAL as a social practice through a literacy process view; an unorthodox alternative is not the only way for the acquisition of EFAL in schools. The above elucidations need to be observed as validations that sustenance the relevance of context to human behaviour and the significance of the subjective belief systems of those involved in research to research processes and outcomes (Nunn and Langille 2016).

In assessing the above statement, the conclusions should not be observed as "a temporal affirmation of objective knowledge that has accrued from traditional/scientific and rationalistic explorations" (Sivasubramaniam 2011,36). This invokes Kohonen et al. (2001), extrapolating that the conclusions should be context-based, context dependent confirmations of a constructivist knowledge, suggested through subjective perspectives of participants through their experiences in High School De Vos Malan. This study's suggestions serve as reinforcements, excluding generalisations of what was perceived as "context bound characteristics" of perspectival/speculative knowledge, evidenced from the data analysis.

\section{REFERENCES}

Adamson, J. L., D. Coulson and N. Fujimoto-Adamson. 2019. Supervisory practices in English-medium undergraduate and postgraduate Applied Linguistics thesis writing: Insights from Japan-based 
tutors. Asian Journal of Applied Linguistics 6(1): 14-27. https://www3.caes.hku.hk/ajal/index. $\mathrm{php} / \mathrm{ajal} / \mathrm{article} / \mathrm{view} / 594$

Atwell, N. 2006. Naming the world. In The supreme importance of reading, J. C. Dana, ed. 1913. Worcester: Heinemann.

Atwell, N. 2006a. A poem a day: A guide to naming the world. Portsmouth, NH: Heinemann.

Atwell, N. 2007b. The reading zone, 247. New York: Scholastic.

Brandt, D. 1990. Literacy as involvement: The acts of writers, readers and texts. Carbondale: Southern Illinois University Press.

Cummins, J., K. Brown and D. Sayers. 2007. Literacy, technology, and diversity: Teaching for success in changing times. Boston: Allyn \& Bacon.

Dyer, J. R., M. Shatz and H. M. Wellman. 2000. Young children's storybooks as a source of mental state information. Cognitive Development 15(1): 17-37.

Foucault, M. 1981. The order of discourse. In Untying the text: A poststructuralist reader, ed. Y. Robert. London: Routledge.

Freire, P. 1993. Pedagogy of the oppressed. New York: Continuum.

Freire, P. and D. Macedo. 1978. Literacy: Reading the word and the world. Connecticut: Bergin and Garvey.

Fall, Z. J. 2013. "I would have no pubes if I were truly in love". Adult Third Rail Quarterly (1): 9-10

Garan, E. M. and G. DeVoogd. 2008. The benefits of sustained silent reading: Scientific research and common sense converge. The Reading Teacher 62(4): 336-344.

Gardner, R. C. 1985. Social psychology and Second Language learning. The role of attitudes and motivation. London: Edward Arnold.

Hall, J. K. 2000. Acquiring intercultural communicative competence from textbooks. Leuven, Belgium: Leuven University Press.

Hendricks, M. 2013. "Not waiting for the initiative to arrive": Teachers promoting and sustaining reading. Reading and Writing 4(1) Art. \#24, 6 pages.

Hoadley, Ursula. 2018. Pedagogy in poverty: Lessons from twenty years of curriculum reform in South Africa. Routledge: London \& New York: Routledge Tailor \& Francis Group

Kepe, M. H. 2017. Building a reading culture among Grade 12 learners in an English First Additional Language classroom: The case of one high school in King William's Town education district. Unpublished $\mathrm{PhD}$ thesis, University of Fort Hare.

Kern, R. 2000. Literacy and language teaching. New York Oxford University Press.

Khalifa Said. 20116.@RealKhalifax ksaid@tz.nationmedia.com

Kohonen, V., R. Jaatinen, P. Kaikkonen and J. Lehtovaara. 2001. Experiential learning in Foreign Language Education. Harlow: Longman.

Krashen, S. D. 2004. The power of reading: Insights from the research. $2^{\text {nd }}$ Edition. Westport CT: Libraries Unlimited and Portsmouth NH: Heinemann.

Lewis, C. 1997. The social drama of literature discussions in a fifth/sixth-grade classroom. Research in the Teaching of English 31: 163-220

Mullis, I. V. S., M. O. Martin, P. Foy and K. T. Drucker. 2012. PIRLS 2011 International Results in Reading. Chestnut Hill, M.A.: Boston College

Nunn, R. and L. Langille. 2016. Operationalizing a global and holistic characterization of competence in a local UAE context. In Trends in language assessment research and practice: The view from the Middle East and the Pacific Rim, ed. V. Aryadoust and J. Fox, 302-316. Newcastle: Cambridge Scholars Publishing.

Rosenblatt, L. 1978. The reader, the text, the poem: The transactional theory of the literary work. Carbondale, Illinois: Southern Illinois University Press. 
Rosenblatt, L. 1995. Literature as exploration. New York: The Modern Language Association of America.

Smith, F 1986. Insult to intelligence. New York: Arbor House. Re-printed Portsmouth, NH: Heinemann, 1998.

Sivasubramaniam, S. 2011. Coming to terms with EIL competence. From defining EIL competence to designing EIL learning. Asian EFL Journal Press for the EIL Journal 1(1): 35-65.

Stranger-Johannessen, E. and B. Norton. 2017. The African storybook and language teacher identity in digital times. The Modern Language Journal 101(S1): 45-60. https://doi.org/ $10.1111 / \bmod 1.12374$

Taylor, S. J. and R. Bogdan. 1998. Introduction to qualitative research methods: A guidebook and resource. $3^{\text {rd }}$ Edition. Hoboken, NJ, US: John Wiley \& Sons Inc.

The Citizen. 2016. "The fading reading culture in Tanzania". Tuesday 20 December 2016.

Vygotsky, L. S. 1978. Mind in society, 57-78. Cambridge, MA: Harvard University Press.

Worldatlas.com/articles/what-languages-are-spoken-in-africa.html. 11 October 2018. https://www. worldatlas.com/articles/what-languages-are-spoken-in-africa.html

Witt, D. 2003. Chapter one: Foundations of the constitutional order. Review of Central and East European Law 28(3): 279-320. doi: 10.1163/157303503773821221

Wolff, H. E. 2016a. Language and development in Africa. Perceptions, ideologies and challenges. Cambridge: Cambridge University Press. 